\title{
Conceptual Framework for Business Process Engineering: Case Study
}

\author{
Željka Car ${ }^{1}$, Antun Carić ${ }^{2}$, Hrvoje Belani ${ }^{1}$ \\ ${ }^{1}$ University of Zagreb, Faculty of Electrical Engineering and Computing, \\ Department of Telecommunications, Unska 3, HR-10000 Zagreb, Croatia \\ \{zeljka.car, hrvoje.belani\}@fer.hr \\ ${ }^{2}$ KATE-KOM d.o.o., Research and Development Department, \\ Drvinje 109, HR-10000 Zagreb, Croatia \\ acaric@kate-kom.com
}

\begin{abstract}
The paper discusses a conceptual framework applied in the requirements engineering process for $e$ school application, offering a service for information society. The e-school application is considered as a fusion of electronic business and mobile business contexts, containing three dynamic-generated Webinterfaces and SMS-interface. Implementation of this service requires changes in the school business process it supports. Paper presents a requirements engineering framework which aims at resolving this feedback loop between the application and business process. Presented framework has been defined in order to efficiently develop the application that provides a service and to, at the same time, ensure necessary identification school business process changes and their models. The framework should also provide the mechanism for efficient service deployment and its future evolution, without adverse effects on the underlying business process. A case study with $e$ school notification service within this framework was implemented has been described.
\end{abstract}

\section{Introduction}

Requirements engineering is established as software engineering discipline because of the recognized need for systematic approach to the earliest phases of software application development. Components of requirements engineering are requirements development and requirements management [1]. Assumption for the successful software requirements development is efficient capturing of business process that the developing application ought to support.
The conceptual framework proposed here tends to coordinate requirements engineering activities for obtaining high level of concurrency in development, and ensuring efficient co-development both of future targeted application and the relevant business process. The corresponding case study is presented, but the authors claim generality of the framework in similar cases, where development and implementation of the business process system implies changes to the process itself. Presented requirements engineering framework was successfully applied in the e-school application case study ${ }^{1}$. This case study was chosen due to the increased interest among schools in exchanging notifications with school-regarding information [2]. As main notification assets were recognized SMS and email, extended with support of rich Web interfaces.

The paper is organized as follows: in sequence of this section the traditional school issues and e-school aspects are discussed. Section 2 presents the conceptual frame-work for business process engineering, while section 3 emphasizes the impact of the prototype on the school business process. Section 4 describes the e-school notification service implementation regarding the presented framework. Section 5 elaborates experiences from the e-school case study. Final conclusion is given in section 6 .

\subsection{Traditional school issues}

Every educational system, along with its core activities of teaching and learning, relies on a set of business procedures and regulative. These procedures fall within the scope of school business process.

\footnotetext{
1 The SMS SNS (Short Message Service School Notification System) project was supported by the Croatian Ministry of Science, Education and Sports (t-Project No.5008).
} 
Example of the traditional school business process segment is modeled (Figure 2.a) regarding student's responsibilities to accept all given tasks and do homework, in order to gain better knowledge. Parent's role in this process is to be informed about his child's grades and learning progress.

Although the significant ICT investments and recommendations have been made into the Croatian educational system in the last few years [3], there are still a number of issues to be properly dealt with, such as: lack of overall e-school system architecture according to technical standards and existing business processes, lack of conditions, rules and procedures for e-school implementation, inadequate tools and practices used in e-learning and e-teaching, and presence of gap between big and small schools. Likewise, the parents as a part of these communities arguably want not only to be timely informed about the activities of their children but to have a tool which will support their active participation in education of their children.

\subsection{E-school information system}

As response to the stated issues, general overview of application for educational process support has been proposed and widely discussed recently in Croatia [3]. Among different areas of interest, the main attention of the case study in this paper is given to the e-school application [4]. Generally, e-school is regarded as the information system for school-related information storage and exchange. Specificity of such systems is in mandatory role-based information access and its confidentiality.

Main purpose of the system is automation of school activities and processes, systematization and unification of syllabuses, and a more active participation of parents in the educational system of their children [5]. Final goal of the whole educational process information system is achievable only when all comprising applications are developed and implemented with the following features kept in mind:

- Each application is developed efficiently and leave it open for future integration, and

- Special attention is paid to the underlying business process. Each application covers a strictly defined process segment without influencing other segments.

Since it is expected that implementation of particular applications will introduce process changes, and because it is necessary to ensure co-development of the application and the process, overlapping of the application impact on different process must be allowed. Requirements engineering discipline in developing such applications is much more than just a start of the standalone business process system development. Every impact on the process and its change proposal should be analyzed in the context of future educational platform. Since the applications are implemented one at a time, a new application could change the process supported by the previous one. Process must be introspected and changes defined by the relevant rules.

\section{Conceptual framework}

The framework has been established within requirement engineering discipline. It covers capture and modeling the business process, elicitation of business and technical requirements for supported application and proposing the process changes requested for satisfactory application implementation. The framework was originally developed for the particular case study, but is not strictly limited to its domain. Figure 1 shows the essential elements of the framework.

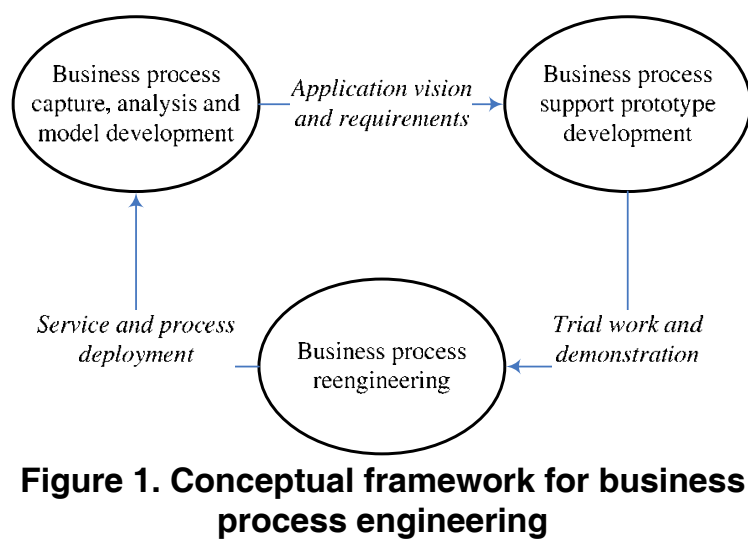

Business process capturing and modeling. Initial boundaries of the (school) business process are identified. Basic understanding of the process is acquired. The process is described and modeled. The process actors are analyzed and service user groups are identified. The activities performed by each user group are stated and modeled. The requirements elicitation techniques associated with this stage are observations, interviews and brainstorming sessions. For better process insight, particular class was identified in one high school [2]. All lesson materials, references, books, homework assignments and exchanged information within a defined time period were screened. 
Application vision and business model definition. Stakeholders' requirements are gathered and mapped into service features, to produce high-level functional specifications. Questionnaires are prepared and distributed to the identified groups of users. This activity should be based on a clear vision and promising business model. Discussion with authorities should be opened here. In the case study it was Croatian Institute for Development of Education.

Prototype development. Service prototype is designed and implemented according to the requirements specification. Prototype aims to verify and complete user requirements gathering, and to provide more concrete features available by the notification service to its users. Demonstrations and discussions with teachers and parents very clearly showed that their changing focus during the process. At early school years their attention is on homework assignments, later it is moving on absence from school. At this point Croatian Ministry of Science, Education and Sports has been involved and financially supported the project.

Trial work and demonstration. Trial work is not only important to verify the functionality and performance of the application but to verify the school process as well. Weaknesses of the process are emerging, so proposals for process changes must be explicitly defined and clearly presented to all process actors. The regularized rules must contain: original process description, functional requirements of the new service and implications on the business process. Also, each process change must be unambiguously stated and illustrated. New process model must be clearly understandable to the users. It is very important to include not only teachers of informatics but wide range of teachers, especially those less informatics literate, as well as school principals.

Business process reengineering. The only way to propose acceptable process changes is collecting the proposals directly from the process actors. Their on topic feedback is valuable from technological and social aspects. Process actors can be regarded as domain experts in the field. Consequently, requirements specifications should be refined and users' feedback about process changes collected. Appropriate techniques here are questionnaires, interviews, small group discussions and specialized workshops. The phase results with valid documents and directives accepted by Institute for Development of Education and approved by the Ministry.

Service and process deployment. Finally, service and improved process are deployed and schools set in motion to use it, mobilizing all actors, especially teachers. The requirements are changeable and users' representatives should be involved in all development iterations, especially deployment. Adequate users training should be ensured, and support of service experts is highly recommended. These are key success factors for this phase. Regular presentations of the development activities and control of the changing requirements are aimed to ensure service quality. Any change reflected on the process is promptly introduced in new process model and discussed with the actors, to eventually be implemented in the next cycle.

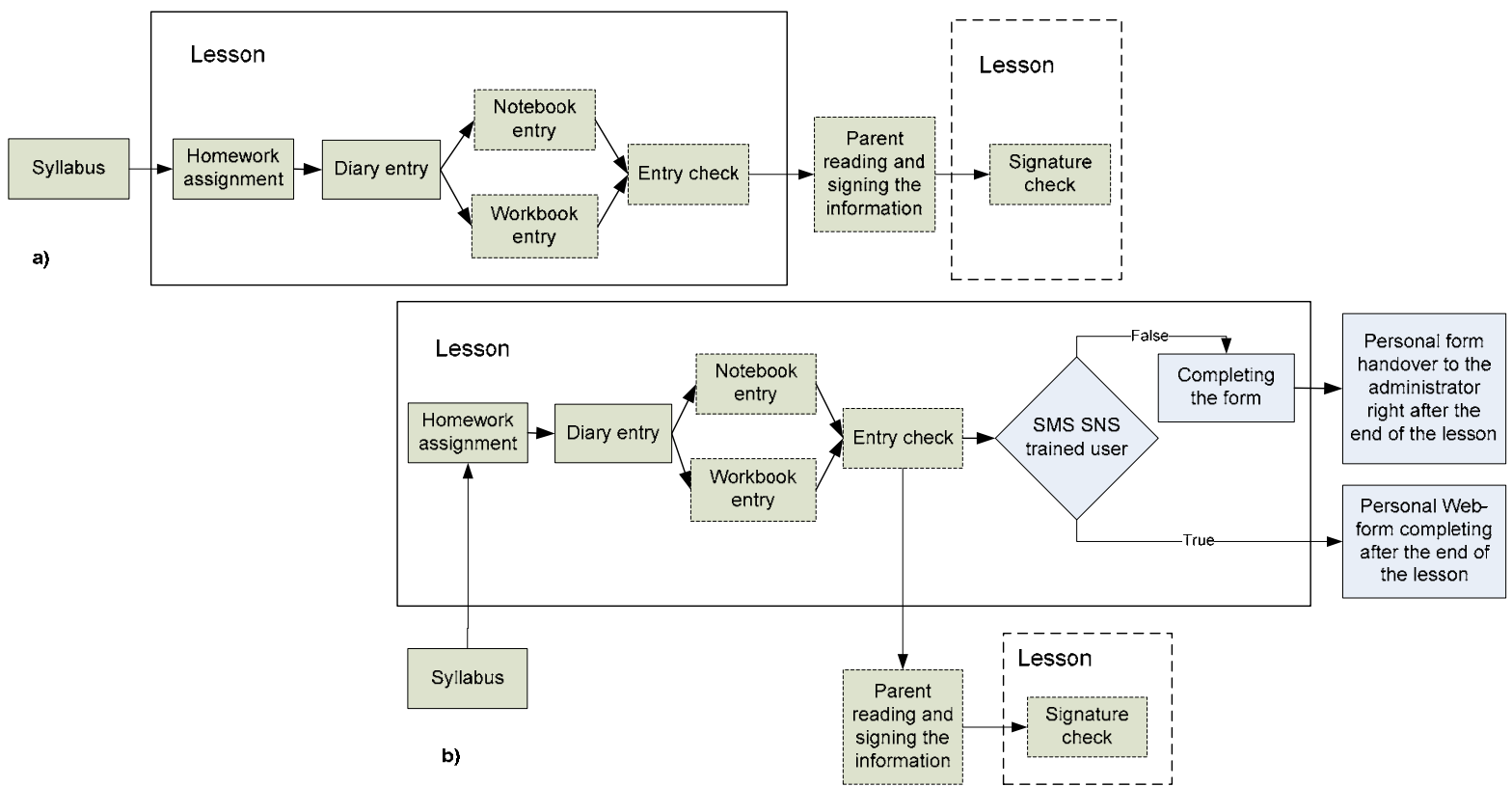

Figure 2. Business process segment dealing with homework assignment, modeled from the: a) traditional school business process, and b) improved school business process supported by the e-school application 


\section{Application impact on the business process}

Very important prerequisite for employment of the case study service was that teachers slightly change their homework assignment records and other information, such as students' absence. Every school has an established procedure for tracking these data and alerting parents when it is considered necessary. This kind of communication with parents is time consuming. One of the risks associated with service usability is directly related to moderation of this procedure (Figure 2.b) and avoidance of additional administrative work to the teachers. Another challenge is related to the overall idea of e-school, and while dealing with the particular service requirements, a whole set of future features must be taken into consideration.

The key idea is to initiate e-school system with gradual support of school process changes necessary for successful implementation and integration of technology in the effective educational system. Also, the assumed process changes should directly impact the requirements set for a particular e-school application.

Improved school business process is an addition to the traditional process and supposes the successful usage of the implemented notification service with all associated activities. The important assumption is that introducing the improved business process will not decrease the level of usability and conveniences to the actors. Change of existing procedure is inevitable as is very important to avoid teacher's writing same information twice.

\section{4 e-School Notification Service}

The case study represents e-school application offering notification service (Figure 3.) for schoolregarded information exchange, at any point and at any time using mainly SMS messages. This service enables fast, simple and cheap mean of information exchange between schools, parents and students [2]. Notifications are about homework assignments, student absence, general notification, or information about teacher-parent meetings, etc. Broadcast possibilities are included using distributed componentbased architecture [5]. A bidirectional communication is enabled since parents can ask for particular information they wish to receive via SMS, and the teachers can send any information about the children via SMS [6]. Data entry is achieved using secure Web interfaces [7] [8]. The service enables customizing parents' profile and receiving only information of interest.

Notification service users are teachers as content administrators, also system administrators, parents and students. Any registered school employee is responsible for entering the school-related information into the system and can have content administrator role. The role of a system administrator depends on the service business model. It can belong either to service provider party or to the school. If the system is hosted by the school, then teachers can also be system administrators.

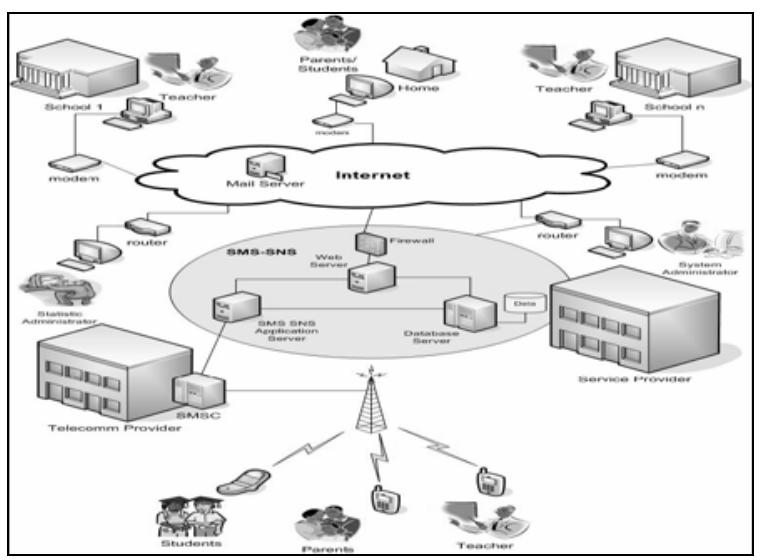

Figure 3. SMS SNS physical architecture model for large area [12]

\subsection{Service Development}

Although the simplicity of the notification service usage, appropriate software development process is required to implement it. Software development process applied in the case study was Rational Unified Process (RUP) [13], rather tailor-able process [8]. Figure 4 shows concurrent development of e-school application and school business process. With the conceptual framework assigned, several stages within the requirement engineering discipline were defined. Each stage was defined according to the goal, and associated to requirement elicitation techniques.

\subsection{SMS SNS Web Interfaces}

Although main notification mean of this service is SMS, the service also offers three Web-interfaces. Web is considered more user friendly and extensive communication media, opposite to inherent limitations of SMS. The service offers Web-interfaces for content provider (Figure 5.), system administrator and service users [6]. 


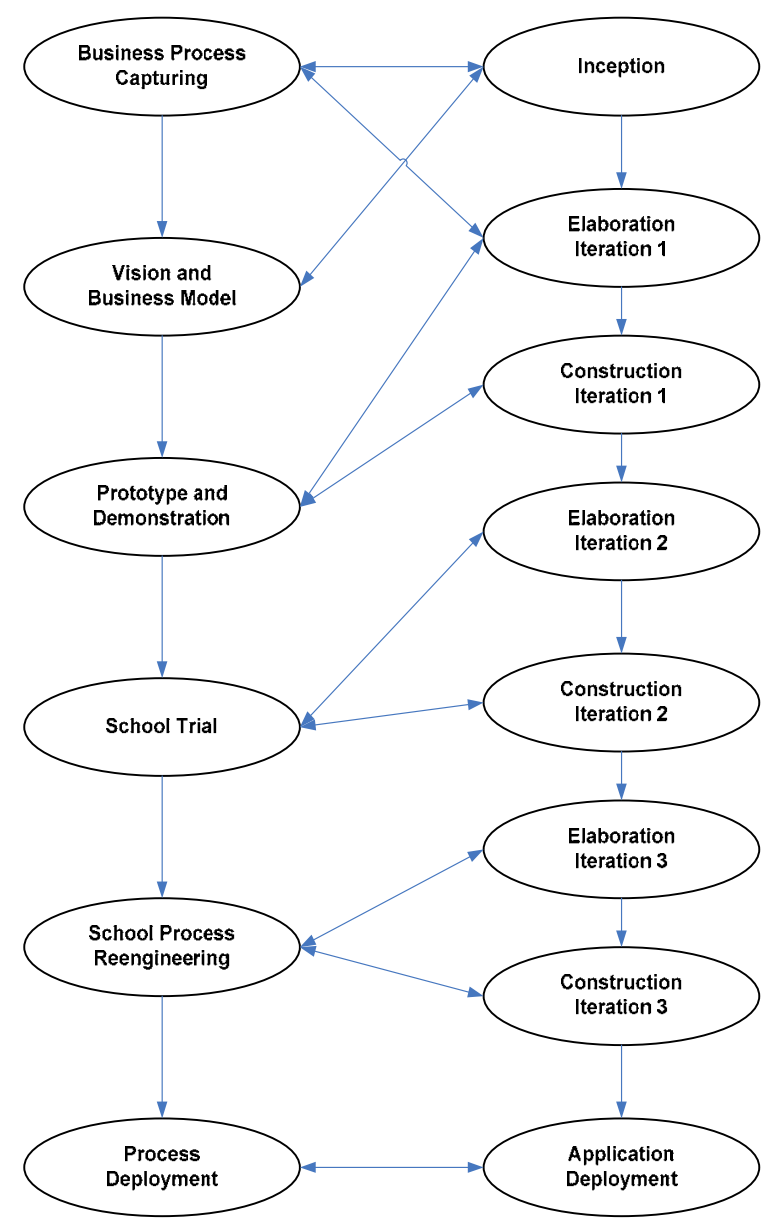

Figure 4. Concurrent development of e-school application and school business process

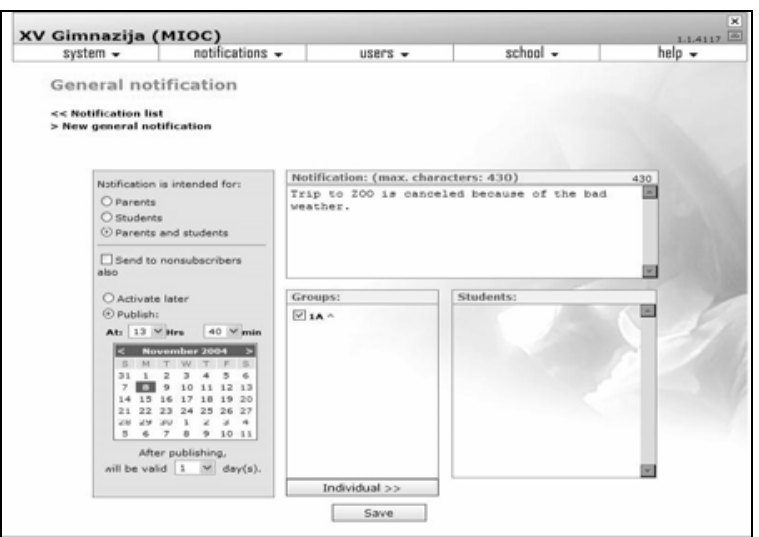

Figure 5. Content provider Web-interface, one of three Web-interfaces the service offers [12]

\section{Case Study Experiences}

Real trial work in one Croatian high school resulted with crucial experiences for on-going e-school implementation. School and teachers were captured in existing process and overloaded by daily work. They were faced with unabridged challenge of change and resistance, and needed help both in application and process implementation. Without significant support, there is a potential risk that system stays empty, i.e. without relevant information, but with disappointed parents.

Regarding conducted case study, the following conclusions are made: The prerequisite for service development is capturing and modeling the adequate segment of the business process to be supported. Thus, requirements engineering discipline embedded in the framework presents more than capturing business process and specifying functional and nonfunctional requirements. Its additional prerequisites are:

- Proposing process changes;

- Surveying process actors about process changes, analyzing their feedback;

- Coordinating requirements engineering activities so that high level of con-currency in development is obtained, and

- Ensuring efficient co-development of the process and future services.

For proposing process changes it is necessary to demonstrate and illustrate all benefits of the service to the process actors. Developing service prototype is the best way for cognitive walk-through the changed process and application. It is important to select a representative group of users. The questionnaires were prepared for each group separately and all the users completed them. The interviewees elaborated on successful implementation of the service and the business process changes. This produced double benefit - process improvement and better service implementation. Each questionnaire contained several parts. General and context-oriented parts were common for all user groups, while the functional part contained differences regarding various view-points, aspects, problems and obstacles related to each user group separately.

Key persons from the particular user groups were interviewed. The interviews were conducted specially with the school administration representatives who would propose the business process changes that need approval and acceptance. The interviews were semi structured, with both predefined questions about a specific issue and opened topics to be discussed. 
Most of the challenges emerged from communication with the users, to describe all benefits of application implementation. Their first impressions from application description were positive. $79 \%$ of the parents thought that their active involvement and knowledge about homework assignments contributed to better learning results. Average parents' and the teachers' score of the need and interest in notification service was 3.75 and 3.84 respectively. These results confirmed the need for such notification service. Most of the teachers' questions were about additional activities that they would have to introduce in their work in order to fully benefit from the application. The teachers were concerned about new activities' impact on their everyday work and on its quality, and of the additional administrative burden.

A prototype demonstration was particularly valuable in communication with future service providers and school authorities, to resolve questions on business model, price, costs etc. However, after the prototype demonstration some doubts were cleared up. Practical questions and suggestions replaced assumptions and concerns.

Therefore, the biggest challenge was to present delayed reaction of the market - parents in this case and to present the whole e-school environment rather than merely a particular notification service. Once the process actors gained full image of the e-school as the integrated environment of notification and supporting applications, the process actor was able to view all benefits of that particular service. At that point he/she participated in the vision with the mindset on the practical issues necessary for improvement of the whole business process. This is a presumption where any additional activity and all process change propositions can be assumed as indispensable for overall process development towards better school quality.

\section{Conclusion}

Given analysis of the conceptual framework for business process engineering showed its suitability for similar projects having common characteristics:

- Capability to capture and analyze business process and develop its model,

- Business driver for business process supported application development, and

- Business process reengineering compliance with the introduction of new applications.

Described e-school case study and the field results of the service operation and usage are successful.
The implementation of applied requirement engineering framework has been proven as justified. The authors claim its generality in similar cases where development and implementation of the business process system implies changes of the process itself.

The success of application implementation and introduction of the proposed business process changes grossly depends on the process actors' commitment and familiarity with the long term benefits of the application and introduced changes. Business process engineering must be performed with caution, and process actors' utilization must not increase significantly. Their effort will probably increase soon after introduction of process changes and after the prototype implementation. In the long-run, their effort will decrease and some other non-quantifiable benefits will occur. Consequently, the success depends mostly on the people, their commitment, their openness to new ideas and the ability to envision future.

\section{References}

[1] Wieger, K., Software Requirements, Microsoft Press, 2003.

[2] N. Rendulić, O. Labor, and Ž. Car, "SMS School Notification Service as Booster for e-School", Proceedings of the SoftCOM, Croatia, 2004.

[3] Budin, L., Bajica, M., Carić, A., Čerić, V., Glavinić, V., Lovrek, I., Manger, I., Ursić, S.: Croatia in 21st Century Information and communication technology. Croatian Development Strategy Office, Zagreb, July 2001. (in Croatian)

[4] A. Carić, D. Huljenić, O. Labor, and Ž. Car, "Architectural Framework for e-School", Proceedings of the MIPRO, Croatia, 2004.

[5] Z. Žunko, N. Jerković, and I. Vukomanović, "Communication Aspects of the Panoptes System", Proceedings of the MIPRO, Croatia, 2004.

[6] M. Mićin, J. Nižić, and D. Obradović: "User Interfaces of the Panoptes System", Proceedings of the MIPRO, Croatia, 2004.

[7] S. Herceg, G. Protega, and H. Belani, "Administration, Management and Security Aspects of Panoptes System", Proceedings of the MIPRO, Croatia, 2004.

[8] Ž. Car, O. Labor, A. Carić, and D. Huljenić, "Tailoring RUP: E-School Project Case Study", Proceedings of the MIPRO, Croatia, 2004

[9] Bosilj Vukšić, V., and A. Kovačič, Business Process Management, Sinergija, Zagreb, May 2004. (in Croatian)

[10] Ž. Car, G. Protega, and C. Krušlin, "Integrating the Software and Documentation Development Processes", Proceedings of the MIPRO, Croatia, 2005.

[12] SMS School Notification Service. Product Description v1.1, KATE-KOM, Zagreb, Croatia, 2004.

[13] Kruchten, P., The Rational Unified Process: An Introduction, Addison-Wesley, 1999. 